\title{
Resource efficiency analysis of high pressure die casting process
}

\author{
Micael Gonçalves $^{(1)}$, Mark R. Jolly ${ }^{(1)}$, Konstantinos Salonitis ${ }^{(1)^{*}}$, Emanuele Pagone ${ }^{(1)}$ \\ (1) Manufacturing Department, Cranfield University, Cranfield, MK43 0AL, UK
}

"Contact details: k.salonitis@cranfield.ac.uk, Tel: +44 (0) 1234758347

\section{Abstract}

Resource and energy efficiency are important for all manufacturing sectors because they impact directly on the economics of the process. In this paper, the resource and energy efficiency of high pressure die casting is analysed and assessed based on real data collected from a number of foundries and supporting companies such as recyclers and ingot producers. The present study is the first to include all lifecycle stages, from the cradle to grave, including recycling loops. The results show that in average only $48 \%$ of the total amount of aluminium poured is transformed into final good products. Of the remainder, $47 \%$ can be recycled (inhouse or by external recyclers) and $5 \%$ is an unrecoverable loss. Furthermore, an average embodied energy for manufacturing aluminium ingots of $33.3 \mathrm{GJ} / \mathrm{t}$ was calculated. Finally, a total energy of $98 \mathrm{GJ}$ to produce 1 tonne of aluminium was estimated.

Keywords: Resource efficiency, Embodied energy, Aluminium, High pressure die casting, Recycling, Yield

\section{Introduction}

Manufacturing sector is the most energy demanding sector, and, consequently, it is also a major source of environmental pollution. Among the various manufacturing technologies, casting processes are considered as ones of the most energy intensive.

Over the last decades, as a result of a worldwide green and sustainability movements, the manufacturing strategy has changed in order to "maximise the gains from the minimum resources" [1]. This way, Salonitis and Ball suggested the inclusion of sustainability as a key attribute to be considered when making manufacturing decisions [2]. In order to follow this trend and accomplish strict legislations, foundries will have to control their procedures and decrease their energy and resource consumption [3]. In the present study the focus is on high pressure die casting (HPDC) process.

It is a widely used cost-effective casting process to mass-produce metal components where physical dimension must be replicated and surface finish is important, accounting for around $50 \%$ of the aluminium castings produced worldwide [4] [5].

The study of the environmental impact should consider all the stages of the materials, that's means, not only the energy consumed directly through the manufacturing process, but also to extract, prepare, recycle and dispose the materials used in the process [6].

Deming argued "if you cannot measure it, you cannot manage it", thus, the present paper aims to quantify the resources and energy efficiency of HPDC process considering data from the world's leading foundries and introducing the concept of material embodied energy [7]. 
The embodied energy is defined as the energy needed to produce a component and the energy contained in its raw materials [8].

\section{Research Methodology}

In order to study the resource and energy efficiency of HPDC process, two different stages were considered.

Starting with an extensive literature review as to examine existing studies and to identify models which consider all the lifecycle stages. As shown in Figure 1, the "cradle to grave" approach aims to include the energy consumption that occurs due to resource extraction and processing, component and product assembly, use, and end of life processing of a product.

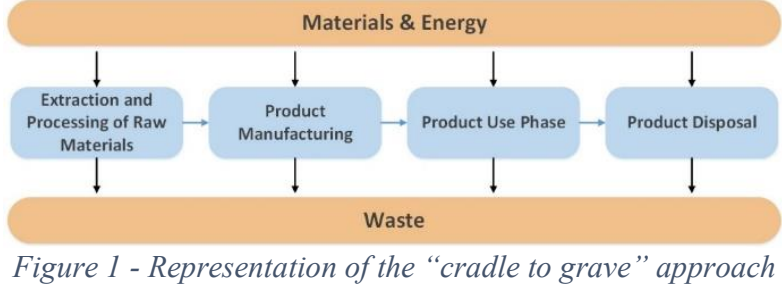

Regarding the "extraction and processing of raw materials" stage, the following processes were considered: mining, smelting and electrolysis. The "product manufacturing" stage included melting, holding, casting, fettling, heat treatment, machining and impregnation processes. Finally, the recycling loops after the product disposal and during the production process.

In order to gather valid information, secondary information (materials composition and raw material embodied energies) from the literature was collected and whenever that was not enough, primary data (resources utilisation, energy consumption, yield and waste) from worldwide recognised manufacturing companies were gathered through interviews. Namely:

- The energy to produce aluminium and other alloying components (copper and silicon) was collected from the literature.

- For the casting process, primary data from manufacturers of HPDC aluminium alloy components were collected through interviews.

- With regards the recycling loops, the common industrial practice is to outsource the aluminium alloy recycling to specialised recyclers rather than at the foundry. Therefore, for this matter recyclers and refiners in UK, France and USA were visited and contacted.

Finally, around 50 companies and industry experts were contacted, most of whom demonstrated much interest in the study.

\section{Case Study - Aluminium Engine Blocks}

The production of aluminium components depends on the casting process, the foundry, the type of product is produced and its quantity. Therefore, in order to collect data about energy consumption and resources utilisation, a case study was selected.

The case study selected was aluminium engine blocks. The automotive industry is the largest market for aluminium castings [9] and the cylinder block is the heaviest single component in a passenger vehicle. Nowadays, as a result of a global approach to replace high density materials 
with lightweight materials, this component is predominantly produced using aluminium alloys (mainly for small and medium engine blocks).

The automotive experts argued that, globally, $70 \%$ of aluminium alloy engine blocks are manufactured through HPDC casting whilst the remaining $30 \%$ are produced using 3 other casting processes ("Cosworth" process, low pressure die casting and gravity sand casting).

\section{Aluminium Production and Recycling}

\section{Primary aluminium production}

The primary production of aluminium contains the energy required to mine, process and convert the mineral ores to primary metal. A study by Jolly and Salonitis determinates the typical energy consumption associated with each step (Bauxite Mining, Aluminia Refining, Anode Production and Electrolysis), based on production data of primary aluminium manufacturers and information published. By adding up all the energies consumed in all the different stages, the production of one tonne of primary aluminium requires 98 GJ. Additionally, the authors underlined that, during the "alumina refining" process, two tonnes of red mud are generated for every tonne of primary aluminium that must be landfilled [8].

\section{Secondary Aluminium}

There are many different sources of waste to produce secondary aluminium, such as, new scrap, old scrap, turnings and drosses. Two main processes can be identified:

- in-house recycling: when aluminium is recycled in foundries, where the products are (or not) produced.

- external recycling: when aluminium is recycled by an external and specialised company.

According to foundry practices, the ratio between the two differs. In the most commonly case among aluminium foundries, the metal collected from production processes (new scrap) is fully reprocessed by external recyclers in a form of closed-loop recycling. The different stages and flow of aluminium products during its lifecycle are described by Jolly and Salonitis [8].

In general, producing 1 tonne of aluminium from scrap consumes only $5 \%$ of the energy that is needed to produce primary aluminium [10]. Based on the figure presented in the previous sub-section $(98 \mathrm{GJ} / \mathrm{t})$, it means $4.9 \mathrm{GJ} / \mathrm{t}$ of aluminium. However, prior to melting aluminium scrap some additional processes are required. Figure 2 represents all the processes considered in the embodied energy calculation.

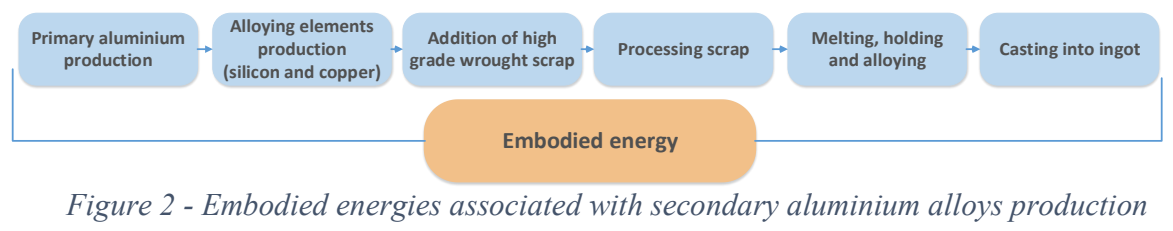

This way, the energy content needs to be supplemented with embodied energies associated with it. In accordance to the literature reviewed, it consists in an extra 5.7 GJ of energy per tonne of aluminium (Table 1) [11]. 
Table 1 - Average energy consumed in aluminium recycling

\begin{tabular}{|c|c|}
\hline Recycling process stage & Recycling energy [GJ/t] \\
\hline Scrap shredding and sorting & \\
\cline { 1 - 1 } Pre-treating (swarf drying) & \\
\cline { 1 - 1 } Melting, holding and alloying & \\
\cline { 1 - 1 } Casting into ingot & \\
\hline
\end{tabular}

Finally, by adding up all the energy consumed, the production of one tonne of secondary aluminium requires $10.6 \mathrm{GJ}$ (other alloying elements are not included).

\section{Other Alloying Materials Energy}

In terms of alloying elements production, for simplicity reasons, only the embodied energies in raw materials (primary silicon and recycled copper) are taken into consideration (Table 2). However, it is worth to mention that when master alloys are used, their processing stage involves some additional embodied energy for melting (induction and reverberatory furnaces) and the usage of extra primary aluminium to eliminate the possibility of adding impurities and thus providing required master alloy specification.

Table 2 - Embodied energy in manufacturing metallurgical grade silicon and recycled copper [12]

\begin{tabular}{|c|c|c|}
\hline Material & $\begin{array}{c}\text { Production energy } \\
{[\text { [GJ/t] }}\end{array}$ & Average [GJ/t] \\
\hline Recycled Copper & $12.8-14.1$ & 13.5 \\
\hline $\begin{array}{c}\text { Metallurgical } \\
\text { grade silicon }\end{array}$ & $116-128$ & 122 \\
\hline
\end{tabular}

\section{Aluminium Refining}

Most of the aluminium applications are made of aluminium alloys. This alloys come from primary or secondary ingot, or both.

The process of recycling aluminium scrap to form the alloys uses a combination of rotary and reverberatory furnaces, which represent around $90 \%$ of the furnace technology. It allows producing standardised aluminium alloys from a range of scrap sources [13].

\section{Multiple Life Cycle Method}

Because the history of the scrap that is used as a furnace charge or aluminium foundry ingot is not known, according to Brimacombe et al., it is necessary to consider all the stages that the material might go through from initial manufacture to final disposal [6].

Based on the number of product cycles (n), the embodied energy in the material can be estimated by calculation. Equation 1 represents the total energy content for the chosen number of cycles and can be calculated as follows [6]: 


$$
X=\left(X_{p r}-X_{r e}\right)\left[\frac{(1-r)}{\left(1-r^{n}\right)}\right]+X_{r e} \quad \text { Equation } 1
$$

According to Equation 2, the energy burden for multiple recycling, where the material is recycled indefinitely, can be obtained by calculating [6]:

$$
X=X_{p r}-r\left(X_{p r}-X_{r e}\right) \quad \text { Equation } 2
$$

$\mathrm{X}_{\mathrm{pr}}$ stands for energy for manufacturing 1 tonne of material via primary route, $\mathrm{X}_{\mathrm{re}}$ for the energy for manufacturing 1 tonne of material via recycling route, $r$ is the overall recycling efficiency over one life cycle $(\mathrm{r}=\mathrm{RR} * \mathrm{Y}), \mathrm{RR}$ is the scrap recovery rate [\%] and $\mathrm{Y}$ stands for the efficiency of the recycling process [\%].

In order to calculate the embodied energy of aluminium alloys according to the multiple life cycle method, the values for the aluminium scrap recovery rate and refining process yield were collected from the literature [13] [10] and recycling companies. The final values are presented in Table 3.

Table 3 - Aluminium scrap recovery rate and efficiency of the recycling process

\begin{tabular}{|c|c|c|}
\hline Aluminium & $\begin{array}{c}\text { Recovery rate RR } \\
{[\mathbf{\%}]}\end{array}$ & $\begin{array}{c}\text { Efficiency of the recycling } \\
\text { process } \mathbf{Y}^{\mathbf{1}}[\mathbf{\%}]\end{array}$ \\
\hline Foundry scrap & 100 & 95 \\
\hline Automotive scrap & 95 & 90 \\
\hline Mixed scrap & $85^{2}$ & 85 \\
\hline
\end{tabular}

${ }^{1}$ Yield of the refining process strongly depend on the type of furnace, scrap and its level of contamination.

${ }^{2}$ Average based on different products end-of-life recovery rates.

\section{Aluminium recycling route}

Regarding the case study, most of the engine blocks are made totally from secondary ingot. The alloy used for HPDC is A380 or A383.

The recycled aluminium can have the same properties as primary aluminium. However, in a course of multiple recycling, more and more alloying elements are introduced into the metal cycle. Secondary alloys have relatively high levels of impurities, especially iron, that is detrimental to many properties, mainly castability and ductility, and it must be kept at the lowest levels possible. If the chemical analysis of molten scrap does not fit into the specification of the secondary casting alloy, the mixture needs to be 'sweetened' with some primary aluminium, in a form of new wrought processing scrap, high grade aerospace scrap or similar.

Apart from that, some alloying elements need to be added. The ones in a significant amount (considered as more than $1 \%$ ) are silicon and copper. Silicon and copper can be added as pure metal, concentrated powder tablets or master alloy [14].

Based on most common industry practices, two main recycling routes can be specified closed loop and open loop product (however, in both cases material is in a closed loop system, 
where "no changes occur in the inherent properties of the recycled material" - ISO 14041 [15]) (Figure 3).

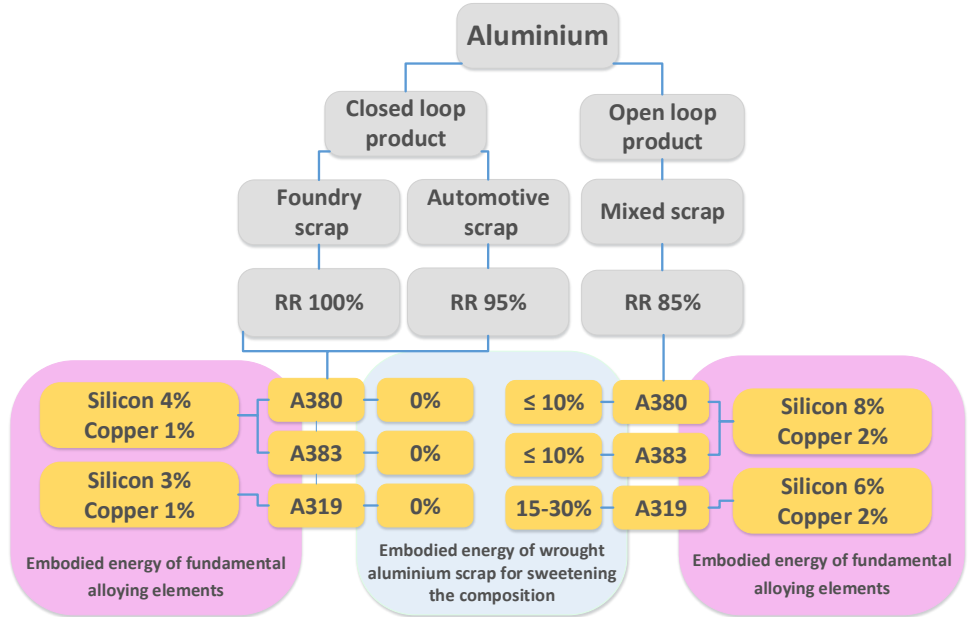

Figure 3 - Aluminium recycling routes ( $R R$ - recovery rate), displaying the closed and open loop recycling scenarios to produce the considered alloys and how it impacts the percentage of primary aluminium in ingots and other alloying elements addictive.

Figure 3 will be a base for best and worst case scenario calculation. The average values for the amount of the wrought scrap and alloying elements added during melting stage was decided upon collected data from aluminium refiners.

\section{Calculation of Embodied Energy}

\section{Aluminium Ingot}

Considering the multiple life cycle method and its variables, the energy for secondary aluminium ingot produced in a course of refining process according to the number of recycling loops is presented in Figure 4.

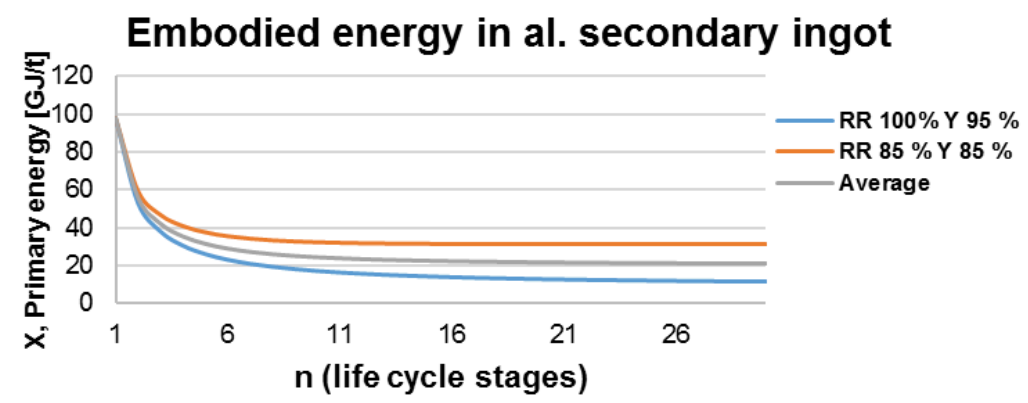

Figure 4 - Energy embodied in aluminium scrap processed into foundry ingot $\left(X_{p r}=98 \mathrm{GJ} / \mathrm{t} ; X_{r e}=5.7 \mathrm{GJ} / \mathrm{t}\right)$

Thus, Table 4 represent the final calculation for the embodied energy including wrought scrap and alloying elements for infinite life cycles. 
Table 4 - Summary of total embodied energies for manufacturing al. foundry ingot

\begin{tabular}{|c|c|c|c|}
\hline Scenario & $\begin{array}{c}X \text { for } n=\infty \\
{[G J / t]}\end{array}$ & $\begin{array}{c}\text { Additional } \\
\text { Embodied Energy }\end{array}$ & Total \\
\hline $\begin{array}{c}\text { RR } 100 \% \text { Y } 95 \% \\
(\text { WS } 0 \%, \text { Si } 4 \%, C u 1 \%)\end{array}$ & 10.4 & 5.0 & 15.4 \\
\hline $\begin{array}{c}\text { RR 85\% Y 85\% } \\
\text { (WS } 10 \%, \text { Si } 8 \%, \text { Cu } 2 \%)\end{array}$ & 31.4 & 19.8 & 51.2 \\
\hline \multicolumn{3}{|c|}{ Average } & 33.3 \\
\hline
\end{tabular}

WS - wrought scrap, $\mathrm{Si}-$ Silicon, $\mathrm{Cu}$ - Copper

\section{In House Recycling}

To undergo a full energy analysis, the influence of recycling and reusing material in the casting process should be also considered [16]. The residue metal that can be again remelted comes from fettling (in a form of runners and feeders), rarely machining (swarf) and internal inspection. The energy calculations are also based on multiple life cycle method. This way, primary route energy is the ingot energy $(33.3 \mathrm{GJ} / \mathrm{t})$, calculated in the section above. Recycling route energy includes all the processes to recover the aluminium, including casting, melting, holding and fettling - around $15.2 \mathrm{GJ} / \mathrm{t}$. The through process yield is the percentage of material recoverable (1-unrecoverable losses) - $96 \%$, and the recovery ration is the net scrap produced $-37.2 \%$ (it includes fettling and internal quality losses). These figures were collected from a large HPDC foundry. Figure 5 represents aluminium embodied energy that is recycled or reused in-house. For infinite life cycles, it represents $26.8 \mathrm{GJ} / \mathrm{t}$ of aluminium remelted.

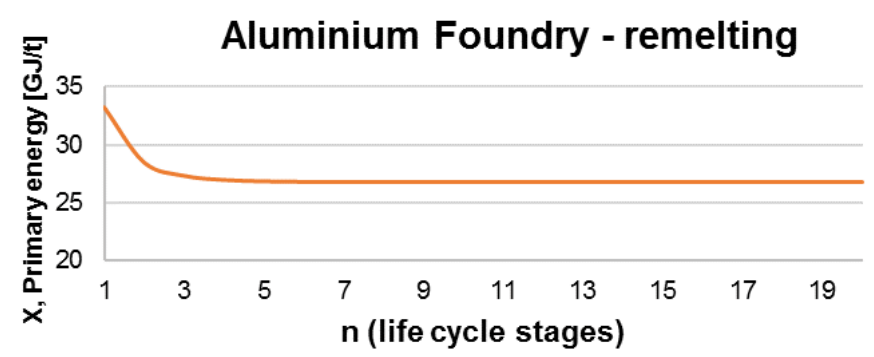

Figure 5 - Energy embodied in aluminium collected from the production stage and remelted in-house in the foundry $\left(X_{p r}=33.3 \mathrm{GJ} / \mathrm{t} ; X_{r e}=15.2 \mathrm{GJ} / \mathrm{t} ; \mathrm{Y}=96 \% ; R R=37.2 \%\right.$ )

\section{Total Embodied Energy for HPDC}

Finally, in order to study whole lifecycle production, it was collected processes energies and materials losses about the case study selected.

Based on this information and the calculations earlier explained, a Sankey diagram (Figure 6) was developed to summarise and visualise the energy and material flow within the different production processes for HPDC. 


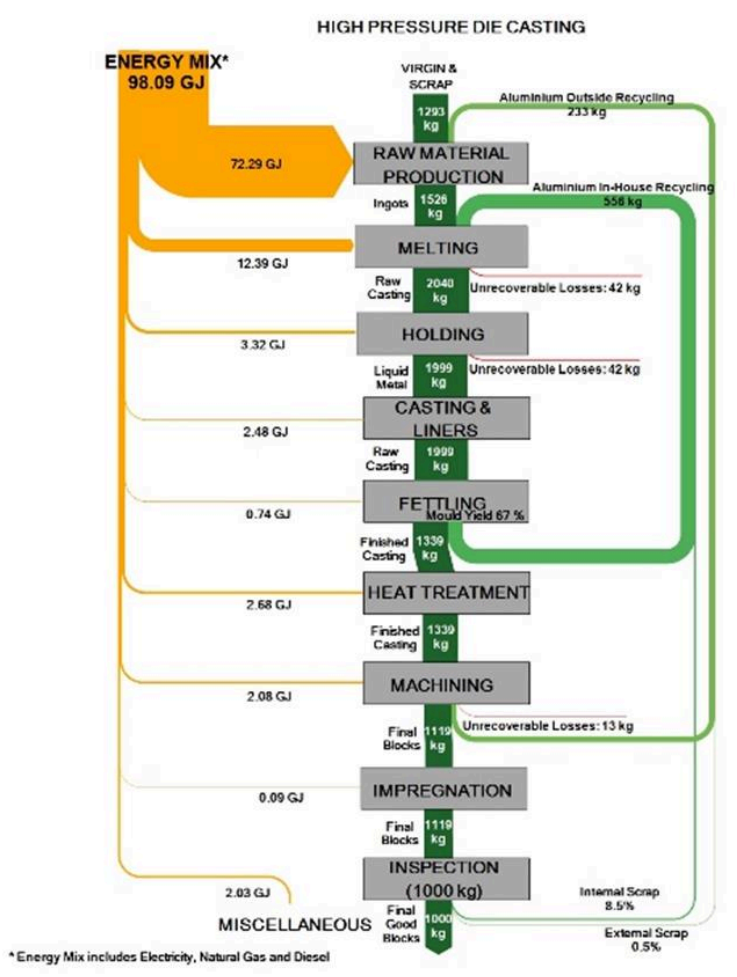

Figure 6 - Energy and material flow in HPDC, showing that for $2080 \mathrm{~kg}$ of charged material in the melting results in $1000 \mathrm{~kg}$ of aluminium good products and $98 \mathrm{GJ}$ of energy consumed

\section{Key findings}

The study carried out revealed the following findings:

- Most of the energy, $72.3 \mathrm{GJ} / \mathrm{t}$ of final products $(74 \%)$, is consumed in the production and recycling of the raw material - aluminium, silicon and copper.

- Three different sources of aluminium can be used: primary aluminium, aluminium ingot (the most common) and recycled scrap - 98, 33.3 and $26.8 \mathrm{GJ} / \mathrm{t}$ are consumed respectively.

- The foundry processes consumes $25.8 \mathrm{GJ}$. Melting is the most energy consuming process (12.39 GJ). From the total aluminium melted (commonly referred as charge), $63 \%$ is bought to external recyclers (ingots) and $37 \%$ is recycled internally from internal scrap.

- To produce 1 tonne of good products, 2.08 tonnes has to be melted due to process losses. Based on the number presented above, it means 1.31 tonnes of aluminium from external recyclers and 0.77 tonnes recycled internally.

- Fettling is the process where more material is collected to recycle internally or sold to an external recycling company $-33 \%$ of the total material casted. For the production of engine blocks, machining and inspection also represent considerable percentages of losses due to their complex geometry. In machining, it represents $18 \%$ of the total finish good casting, and, in inspection, $9 \%$ of the engines blocks.

- There is around $5 \%$ of unrecoverable losses, mainly due to oxidation in the melting and holding processes. 
- The Operational Materials Efficiency is $48 \%$, which means that only $48 \%$ of the total amount of aluminium poured is transformed in final good products.

- The total Process Energy Burden is $98 \mathrm{GJ} / \mathrm{t}$ of good castings.

\section{Conclusions}

Within this paper, a detailed analysis and assess of resource and energy efficiency of HPDC is presented. The study considered every step in the manufacturing process and recycling loops, from mining through to disposal phase. The present results are based on a comprehensive survey of aluminium supply industries.

The result clearly indicates that there is much room for improvements and efforts should be made in order to adopt more sustainable and efficient practices in this sector. Foundries focus on minimising bills rather than control the energy and improve resource utilisation.

The research conducted shows that $52 \%$ of the total amount of aluminium poured is wasted during the casting process, even if only $5 \%$ is unrecoverable. Translating these figures into energies, if it is necessary $98 \mathrm{GJ}$ to produce 1 tonne of aluminium, it means that more than half does not add value to the final product. These figures are based on a yield of $67 \%$ and, according to Jolly and Salonitis, the yields for HPDC can be pushed to just under 70\% [8]. Most of the foundries probably cannot achieve this degree of performance and efficiency. Besides that, it was assumed infinite recycling to provide the best-case scenario for the amortisation of the energy [8].

From this energy, almost three quarters is consumed before the casting process begins, to mine, process, convert and recycle aluminium and others alloying components, such as cooper and silicon. The production of primary aluminium is a high-energy consumption process and, in order to mitigate this impact, many foundries claim the usage of recycled aluminium. Indeed, based on the information of one of the biggest providers of aluminium castings, two of the most common alloys for HPDC are A383 and A380, which are secondary ingots. The energy consumed to produce this alloys is $33.3 \mathrm{GJ}$ per tonne - almost one third when compared to primary aluminium production energy (98 GJ). When the aluminium collected from the production stage is recycled and reprocessed within the foundries, it consumes 25.1 GJ per tonne of melted aluminium.

Although the high-energy expenses have been a significant concern for metal casters, the industry continues to use melting technologies with poor energy efficiency. Besides that, the interviews to aluminium suppliers and foundries showed that they do not know how to assess their companies in relation to the current stage of energy use in the metal casting industry, so it is impossible to manage it.

Improving energy efficiency is an important way to reduce energy costs, increase predictable earnings and reduce the environmental impact of the casting processes. Therefore, foundries engineers should study advanced methods and technologies to increase resource and energy efficiency, instead of only regard the quality and price of casting components. 


\section{Acknowledgements}

The authors would like to acknowledge the supreme effort of the MSc students who supported the research presented namely: Emma Caicedo-Portillo, Micael Teixeira Gonçalves, Yan Huaizhong, Noemi Macura, Spyridon Kokolis-Karolidis, Joseph Tucker and Yanni Yang.

\section{References}

[1] IEA, "Tracking Industrial Energy Efficiency and CO2 emission," 2007.

[2] K. Salonitis and P. Ball, "Energy Efficient Manufacturing from Machine Tools to Manufacturing Systems," Procedia CIRP, vol. 7, pp. 634-639, 2013.

[3] Mark Jolly et al., "Energy Efficiency Status-Quo at UK Foundries: The "Small-IsBeautiful" Project," in The Minerals, Metals \& Materials Series, Arne P. Ratvik, Ed.: Springer, 2017, ch. Light Metals 2017, pp. 917-923.

[4] R. N. Lumley, "Application of novel heat treatments for aluminium high pressure die castings to industrially produced components," International Heat Treatment and Surface Engineering, vol. 3, no. 3, pp. 115-120, 2009.

[5] R. N. Lumley, D. R. Gunasegaram, M. Gershenzon, and R. G. O’Donnell, "Effect of alloying elements on heat treatment response of aluminium high pressure die castings," International Heat Treatment and Surface Engineering, vol. 1, no. 4, pp. 2432, 2010.

[6] L. Brimacombe, N. Coleman, and C. Honess, "Recycling, reuse and the sustainability of steel," Millenium Steel, pp. 31-36, 2005.

[7] W. Deming, "Quality, productivity, and competitive position," Cambridge, MA: Massachusetts Institute of Technology, Center for Advanced Engineering Study., 1982.

[8] Mark Jolly and Konstantinos Salonitis, "Primary Manufacturing, Engine Production and on-the-road CO2: How can the Automotive Industry Best Contribute to Environmental Sustainability?," in 38th International Vienna Motor Symposium, Vienna, Austria, 2017.

[9] The Aluminum Association. (2017, August) [Online]. http://www.aluminum.org/industries/processing/castings

[10] European Aluminium Association, "Environmental Profile Report for the European Aluminium Industry - Life Cycle Inventory data for aluminium production and tranformation processes in Europe," Frankfurt, 2013.

[11] Emma Caicedo-Portillo et al., "Life Cycle Energy Analysis for the Sustainable Production of Passenger Vehicle Engine Blocks," Cranfield University, University Group Project 2016.

[12] CSE Edupack, "Granta - Material Intelligence," 2016.

[13] U. M. J. Boin and M. Bertram, "Melting standardized aluminum scrap: A mass balance model for Europe," Journal of the Minerals, vol. 57, no. 8, pp. 26-33, 2005. 
[14] G. E. Totten and D. S. MacKenzie, , Inc. Marcel Dekker, Ed. New York, 2003, vol. Volume 1: Physical Metallurgy and Processes.

[15] International Standard, "ISO 14041," 1998.

[16] J. M. Allwood and J. M. Cullen, "Sustainable materials with both open eyes," Elsevier B.V., 2012.

[17] Alcoa, "Transforming Annual report 2014," Alcoa Corporate Center, Pittsburgh, 2014.

[18] Energetics Incorporated, "Energy and Environmental Profile of the U.S. Aluminium Industry.," Washington DC: U.S Department of energy, 1997.

[19] J. A. Moya et al., "Energy Efficiency and GHG Emissions: Prospective Scenarios for the Aluminium Industry Second," European Commission, Luxembourg, 2015.

[20] IAI, "Life cycle assessment of aluminium: inventory data for the primary aluminium industry-year 2005 update," World Aluminum, London, 2007.

[21] British Standards Institution, "Aluminium and aluminium alloy ingots and castings for general engineering purposes," 1998.

[22] European Aluminium Association and Organisation of European Aluminium Refiners and Remelters, "Aluminium Recycling in Europe the Road to High Quality Products.," European Aluminium Association, Brussels, 2006. 
2018

Resource efficiency analysis of high pressure die casting process

Gonçalves, Micael

Springer

Gonçalves M, Jolly MR, Salonitis K, Pagone E. (2018) Resource efficiency analysis of high pressure die casting process. In: Light Metals 2018. TMS 2018. The Minerals, Metals \& Materials Series. Springer, Cham

https://doi.org/10.1007/978-3-319-72284-9_136

Downloaded from Cranfield Library Services E-Repository 